\title{
OVER DE WENSCHELIJKHEID VAN STAATSTOEZICHT OP DE LEVENSVERZEKERING-MAATSCHAPPIJEN.
}

De polemiek, die in den laatsten tijd gevoerd is op het gebied van Levensverzekering, en met name betreffende de vraag: al of niet Stratsloezicht? is niet vruchteloos gewoest. De levensverzekering is er zeker beter door bekend geworden, en bij dezen en genen is daardoor stellig een wijziging in meening ontstaan.

Deze gedachte $k w a m$ in mij op bij het lezen van het artikel van den heer Samot in het Juni-nummer van dit tijdschrift, getiteld : „Iets over staatstoezicht op levensverzekering-maatschappijen "

Wil men omtrent den stand der quaestie in Nederland behoorlijk ingelicht zijn, dan komt het mij noodig voor, een kort overzicht te nemen van die gevoerde polemiek en de aanleiding daartoe.

In Juli 1877 diende de directie van de Nationale Levensverzekering te Rotterdam een adres in aan den Minister van Binnenlandsche Zaken, waarin zij Z. E. verzocht den Koning voor te stellen, dat

"de bestaande Koninklijke besluiten worden ingetrokken en aan „de Nederlandsche Maatschappijen vrijheid van bedrijf worde toe"gestaan" of wel ..... dat

, de buitenlandsche Maatschappijen van levensverzekering aan "dezelfde bepalingen worden onderworpen als waaraan de Neder"landsche thans onderworpen zijn of in het vervolg zullen worden."

Dit verzoek grondde zich grootendeels op het niet te loochenen feit, dat de buitenlandsche maatschappijen een groot voorrecht genieten in de geheele vrijheid alhier, terwijl de Nederlandsche maatschappijen haar voorwaarden en tarieven hebben te onderwerpen aan het oordeel der regeering, alvorens zij de Koninklijke goedkeuring kunnen verkrijgen.

Bij haar tweeledig verzoek gaf de directie intussohen zeer uitdrukkelijk te kennen dat zij, na intrekking van bedoelde Koninklijke besluiten, geheele vrijheid van bedrijf het verkieselijkst achtte. 
De „Annalen des gesammten Versicherungs-wesens" konden zich zeer goed met het Rotterdamsche adres vereenigen, mits die vrijheid van bedrijf gepaard ging met verplichte publiciteit. Het (Nederlandsche) assurantie-blad steunde het Rotterdamsche adres op alle punten, en verklaarde zich stellig tegen verplichte publiciteit.

Vervolgens werden door de Kamers van Koophandel, ik meen te Rotterdam en te Amsterdam, adressen van adhresie met het Rotterdamsche adres bij de regeering ingezonden.

In Februari 1878 richtte het Bestuur van de Maatschappij van Levensverzekering te Dordrecht een request aan Z. M. den Koning, waarin het zich verklaarde tegen de vrijheid van bedrijf en daarom op een bepaald toezicht van Staatswege op de maatschappijen van Levensverzekering aandrong, maar waarbij het, evenals bet Rotterdamsche adres, gelijkstelling verzocht van de buiten- met de binnenlandsche maatschappijen.

Het Dordtsche request zag in geheele vrijheid een gevaarlijke proefneming, voornamelijk omdat zeer licht een concurrentie kan ontstaan met te lage premiën, vooral van nieuwe maatschappijen, hetgeen veler val zou kunnen veroorzaken, en de levensverzekering kon in discrediet brengen.

Sedert hebben verscheidene Kamers van Koophandel zich, met of zonder voorbehoud, voor toezicht verklaard, en hebben adressen van adhaesie met het Dordtsche request aan de regeering ingezonden.

Het is onnoodig, al de artikelen te noemen die al voor en tegen het toezicht in verschillende bladen geschreven zijn; intusschen zij hier nog rermeld een artikel van Dr. W. C. VAN MaANEN in No. 39 en 40 (1878) van "de Amsterdammer", die sterk voor toezicht is op de binnenlandsche maatschappijen, maar daarentegen de buitenlandsche geheel vrij wil laten, en die reeds in een paar vroegere artikelen als feuilleton, ik meen in de Nieuwe Rotterdamsche Courant, gewezen had op de contrôle der Maatschappijen, welke in Frankrijk is ingevoerd.

In het verslag der Nationale Levensverzekerings-bank te Rotterdam, voorkomende in de Nieuwe Rotterdamsche Courant van 1 Mei 1878, prijst de Directie dier Bank het Engelsche stelsel aan, en zegt: "De Grondslag der wet van Cave is vrijheid met "speciaal omschreven en aangewezen publiciteit roor alle in het nkoninkrijk werkende maatschappijen. Deze wet werkt uitmuntend."

Ik meende daarop (in de $N . R, C$, van 11 Juni '78) to moeten 
doen opmerken, vooreerst dat verplichte publiciteit niet is geheele vrijheid, dat echter het Engelsche stelsel niet enkel bestaat in speciaal omschreven en aangewezen publieiteit, maar dat elke nieuwe maatschappij, die in het vereenigd koninkrijk wordt opgericht, en elke vreemde maatschappij die er wil gaan werken, bij den Accountant of the Court of chancery een som van 20.000 pd. st. moet deponeeren, waarvan de maatschappij den interest geniet, en welke som de maatschappij terug krijgt, zoodra haar kapitaal, dat men met den naam "reserve" aanduidt en dat tot dekking der risico's dient (life assurance fund accumulated out the premiums) $40.000 \mathrm{pd}$. st. bedraagt.

Tevens maakte ik er opmerkzaam op, dat in Engeland de aandeel- of polishouders een speciaal onderzoek kunnen doen instellen naar den toestand eener maatschappij, en dat de Board of trade na dit onderzoek de ontbinding kan bevelen.

De directie der Nationale $L$. Bank antwoordde mij daarop in de N. R. C. van 23 Juni ' 78 dat zij vrijheid niet onbestaanbaar acht met verplichte publiciteit in voorgeschreven vorm, en wat de storting betreft, zeide zij:

$n \ldots$ en inderdaad is het ons uit geloofwardige bronnen „bekend geworden, dat het voorschrift der Engelsche wet bevelendo " de storting van 20.000 pd. st., alvorens aldaar een nieuwe maat${ }_{n}$ schappij te kunnen oprichten, zijn oorsprong heeft gehad in den " geheimen wensch der toen bestaande maatschappijen, om tegen "lastige concurrentie beveiligd to zijn. Indien dit werkelijk het " doel van die bepaling was, heeft zij aan de verwachting beantn woord. De oprichting van onderlinge maatschappijen werd daarn door bijna onmogelijk gemaakt, terwijl ook die van andere zeer nwerd bemoeilijkt. Het gevolg was dan ook, dat sedert de vitn vaardiging der wet van Cave, slechts enkele nieuwe maatschap„pijen zijn opgericht.

„Zoodanige bescherming nu, waartegen indertijd ook in Enge"land op verschillende gronden is geprotesteerd, verlangen wij niet....."

Nu zal ieder mij toch toegeven, dat men de werking eener wet niet moet toeschrijven aan sommige harer bepalingen alleen, maar, zoo niet aan alle kleine bijzonderheden, dan toch zeker aan al de hoofdbepalingen.

Het recht.der belanghebbenden tot het doen instellen van een onderzoek is stellig geen kleinigheid, en wat de storting betreft, daarmede wordt juist vermeden, hetgeen bet Bestuur der Dordtsche 
maatschappij het meest vreesde, dat namelijk bij geheele vrijheid zich tal van insolide maatschappijen zouden vestigen.

De gevoerde polemiek gaf aanleiding tot het vermelde artikel van den heer Samot, wiskundige der Nationale LevensverzekeringBank te Rotterdam en F. I. A.

In dat stuk wordt op waarlijk uitstekende wijze uiteengezet, waarom een bijzonder toezicht van den Staat op de levensverzekering-maatschappijen noodig is.

Ik kan niet anders dan denken, dat de Directie der Nationale Levensverzekeringsbank zich zeer veel gelegen laat liggen aan het advies van haar wiskundige, den heer $S_{A M O r}$, en dan moet ik een groote, $\mathrm{m}$. i. gunstige wijziging in meening constateeren. Het verzoek om geheele vrijheid is toch bezwaarlijk te rijmen met het betoog der noodzakelijkheid van een Staatstoezicht.

Die noodzakelijkheid dan aangenomen, zijn de groote vragen die de heer S. stelt: "Tot op welke hoogte zal dat toezicht zich uitstrekken? Waar is de juiste grens?"

Twee stelsels worden door den heer S. beschouwd, het Engelsche en het Amerikaansche; zoo sterk hij het eerste aanbeveelt, zoo sterk, of liever nog sterker, veroordeelt hij het laatste.

Het gegeven overzicht der Engelsche wet is zeer juist; onder de groole beginselen dier wet wordt ook genoemd de verplichte storting en nu vrees ik, gezien de bovenvermelde meening der directie van de Nationale Bank, dat de heer S. dit groote beginsel wil rekenen tot de bijzonderheden, waarin nde Engelsche wet naar onze toestanden zou dienen gewijzigd te worden", hoewel dit weder daarmede strijdt, dat de heer $\mathbf{S}$. dit zelf omschrijft als het volgende: $n$ dat, zonder de oprichting van nieuwe maatschappijen te "beperken, in ieder geval toch een onderpand van bona fides van "de oprichters moet worden gevorderd."

De heer $\mathrm{S}$. moge dit nu geen beperlipn van nieuwe opriohting noemen; ik vind toch, dat de directie der Nationale Bank geen ongelijk had, dat die er zeer door wordt brmoeilijkk.

Evenzeer is $\mathrm{m}$. i. het recht tot het doen instellen van een onderzoek een groot beginsel. En ik herhaal, men moet met al de hoofdbepalingen eener wet rekening houden, als men haar werking wil beoordeelen.

De veroordeeling van het Amerikaansche stelsel grondt de heer S. voornamelijk op het groot aantal faillissementen van levensverzekering-maatschappijen in Amerika; maar hij wijst tevens op ontrouw aan plicht van den Amerikaanschen ambtenaar, met het 
toezicht belast (waaronder zijn verregaande omkoopbaarheid) welke de heer $\mathrm{S}$. zclf zegt hier te lande niet te mogen vreezen.

Is het verder billijk die rampen to beschouwen als zoovele gevolgen van het Staatstoezicht? Wil dat zeggen, dat die faillissementen niet zouden plaats gehad hebben onder het Engelsche stelsel? Een omkoophaar ambtenaar moge het bestaan eener maatschappij nog wat helpen rekken, hij zal een solide maatschappij niet insolide maken. Wat omkooping noodig heeft ten einde niet onder te gaan, zou, ook onder de Engelsche wet middel weten te vinden, zijn toestand te verbergen. De Albion heeft het trouwens getoond. Verder moet men niet uit het oog verliezen, dat het aantal faillissementen van levensverzekering-maatschappijen in Amerika inderdaad zeer gering is in vergelijking met andere ondernemingen waarbij geen Staatstoezicht eenige schuld hebben kon.

De bewering van den heer $S$. intusschen, dat een jonge Maatschappij aan Z. M. den Koning het Amerikaansche stelsel durfde verzoeken, heeft opheldering noodig. Zoover mij bekend, zijn er slechts twee verzoekschriften van Levensverzekering-maatschappijen ingediend: dat van de Nationale Bank, vragende bij voorkeur om geheele vrijheid, en dat van de Dordtsche maatschappị,, vragende om Staatstoezicht; in het laatste werden verschillende voorbeelden genoemd van Staten waar toezicht plaats heeft, en daaronder werd, wel is waar, Amerika genoemd, maar werd het Engelsche stelsel uitvoeriger dan eenig ander uiteengezet.

In dat Dordtsche request "meenden adressanten de wijze van "controleeren aldaar (Engeland) niet geheel als voorbeeld to "kunnen aanbevelen", maar wenschten voor ons land een meer bepaald toezicht, vooral ook, omdat in Engeland de levensverzekering veel populairder is, en meer algemeen bestudeerd wordt dan in Nederland. Het eenige tijdschrift toch over verzekering, dat hier hoopte te bestaan: liet Assurantieblud, reeds boven vermeld, heeft niet meer dan zes nummers mogen beleven. In dat request werd dus volstrekt niet het Amerikaansche stelsel aanbevolen, nog minder aangerraagd; het beginsel "direct toezicht" werd aangegeven, niet meer en niet minder. Er zijn dan toch nog wel meer voorbeelden te noemen dan Engeland en Amerika. En bovendien, evenmin als de heer $S$. het Engelsche stelsel copieeren wil, zal wel niemand eenig stelsel ter wereld ongewij zigd willen overnemen $Z_{0 o}$ is het dunkt mij volstrekt niet onverschillig, of het toezicht wordt uitgeoefend door één verant- 
woordelijk persoon, dan wel door een commissie, zooals in Frankrijk geschiedt.

Verder sprekende over dezelfde jonge Maatsehappij, die zulke ongerijmdheden wil, zegt de heer $\mathrm{S}:$ "waarlijk van tweeën één: of men heeft hier te doen met een treurig bewijs van gebrek aan de noodige studie van en de ondervinding in het rak, of met het inwendig besef dat, comme il est des accommodements même avec le ciel, men zich nog zooveel te gemakkelijker met den Staatsambtenaar zou kunnen verstaan."

De onderstelling van dat invendig besef zal ik laten voor wat zij is, het ligt niet op mijn weg daartegen op te komen, hoewel men met mij eens zijn zal, dat zij nog al gewaagd is, en dat het in meer dan één opzicht beter geweest ware, als zij een innendige onderstelling gebleven ware.

En wat betreft de eerste onderstelling, vind ik het nog al sterk om, als men het met iemand niet eens is, hem gebrek aan studie of ondervinding te rerwijten, vooral als men zelf wijst op nde buitengewone moeielijkheid van de theorie der levensverzekering." Intusschen houd ik die buitengewone moeilijkheid voor wel wat overdreven. Het moeilijke dat de levensverzekering onderscheidt van andere financieele operatiën ligt immers, zoo niet geheel en al, dan toch zeker voor verreweg het grootste deel, in de wiskunde; en nu meen $\mathrm{ik}$, dat iemand, die doctor is in de wis- en natuurkunde (wiskundige richting) of met goed gevolg examen heeft gedaan als leeraar in de hoogere wiskunde bij het middelbaar onderwijs, wel ondersteld kan worden met eenige studie al tamelijk spoedig op de hoogte te kunnen zijn van de wiskundige theorie der levensverzekering. Inderdaad, de mannen der wetenschap hebben wel zwaarder vraagstukken op te lossen dan het berekenen van tarieven, het opmaken van de waarde der polissen, zelfs dan het samenstellen van sterftetafelen, al biedt het laatste werkelijk moeilijkheden aan.

De bewering der ondoenlijkheid van een staatstoezicht op grond van die buitengewone moeilijkheid brengt de heer $S$. in tegenspraak zoowel met de Engelsche wet als met zich zelven. De Engelsche wet toch beveelt wel degelijk een onderzoek op verzoek van polis- of aandeelhouders. Waarom zou dit nu uitvoerbaar zijn als partieulieren het initiatief nemen, en niet als de Staat het uit eigen beweging beveelt? Laadt bovendien de board of trade bij zijn vitspraak geen verantwoordelijkheid op zich, en staat die in voor al de gevolgen? 
In het (Rotterdamsche) Zondagsblad van 5 October '78 zegt de heer S. dan ook zelf:

„Daarom zou het wellicht hier (namelijk bij begrafenisfondsen) "noodig zijn, dat de Staat tusschenbeide trad, en door deskundigen „een onderzoek naar den toestand dezer fondsen deed instellen. ${ }_{n}$ Hieruit zou dan moeten blijken, of wat zij op dit oogenblik in „kas hebben, voldoende is tot dekking van de loopende risico's, "dat is, of zij in het bezit zijn van datgene wat een levensver"zekering-maatschappij haar Reserve noemt."

Alsof het onderzoek naar den toestand van een begrafenisfonds zooveel gemakkelijker zijn zou dan bij een Maatschappij van levensverzekering, - het tegendeel is waarschijnlijker - en alsof de Staat bij zulk onderzoek ook geen verantwoordelijkheid op zich- zou laden!

Ik meen uit een en ander te mogen opmaken, dat de heer $\mathrm{S}$. bij zijn waardeering der versehillende stelsels niet van eenige partijdigheid is vrij te pleiten; terwijl hij zich met betrekking tot het Engelsche stelsel wel wat tot dweeperij schijnt te laten vervoeren, zooals dan ook de aanvang van zijn artikel terstond aantoont, wijst het slot op een vervolging quand même van het Amerikaansche stelsel. Want hoe het mogelijk is, dat de verbazingwekkende vlucht die de levensverzekering in America neemt, als laatst en beslissend argument moet dienen tegen het daar in gebruik zijnde toezicht, verklaar ik niet te kunnen vatten.

Ondanks het vele goede, dat het Engelsche stelsel ongetwijfeld heeft, geloof ik toch, dat er wel een stelsel is in te voeren, dat den verzekerden meer waarborg geeft.

Verplichte publiciteit is zeker uitmuntend, is zelfs een der eerste vereischten waar men de Maatschappijen niet aan zich zelven wil overlaten; maar zij is gegrond op het vertrouwen dat die opgaven naar waarheid en te goeder trouw worden gedaan. De heer $\mathrm{S}$. beweert wel, dat wij geen wet van wantrouwen noodig hebben; maar het ware te wenschen, dat wij niet nog zoo onlangs zaken gezien hadden die voor langen tijd wantrouwen gezaaid hebben, al gold het dan ook geen maatschappij van levensverzekering. Bovendien acht de heer S. kwade trouw zoo weinig onmogelijk, dat hij al heel spoedig aan ${ }_{n}$ accommodement" denkt. Bovendien wat zou het een weinig aangenaam krakeel geven, als de contrôle ten slotte bestond in een onderling critiseeren en verdacht maken van de maatschappijen! 
De storting van een kapitaal door nieuwe maatschappijen is een gedeeltelijke waarborg, maar die ophoudt bij. de teruggave.

Het recht van polis- en aandeelhouders om een afzonderlijk onderzoek te doen instellen heeft stellig groote waarde; minder goed is het, dat dit weer bemoeilijkt wordt door dat men eerst, voor de kosten moet instaan, hetgeen een vrij duur recht kan geven, en dat de Staat zelf dit recht niet heeft.

Volkomen zekerheid is met geen enkel stelsel te bereiken; maar acht men levensverzekering een volksbelang, dan moet men meer waarborg geven voor de soliditeit der Maatschappijen dan de Engelsohe wet aanbiedt, en dit is toch wel te bereiken zonder nu juist de maatschappijen in alle opzichten aan banden te leggen.

Vele bepalingen der Engelsche wet konden dan ook hier worden toegepast, maar wat de Engelschen alleen meenen te moeten doen op aanzoek van belanghebbenden, kon hier direct van den Staat uitgaan; dan zou met name het kapitaal tot dekking der risico's moeten beoordeeld worden, en hierbij moeten worden nagegaan of steeds die grondslagen gebruikt worden welke de statuten aangeven. De wet kon dan de maatschappijen verplichten dat bedrag te beleggen in inschrijvingen op het grootboek, alleen vervreemdbaar na machtiging in naam van den Staat, en verbonden voor de gesloten verzekeringen. Gebeurde het dan, dat een maatschappij haar overige kapitalen ongelukkig had belegd, of zich te groote uitgaven had veroorloofd, dan kon daardoor wel het kapitaal der aandeelhouders verloren gaan, maar de reserve bleef het eigendom der polishouders; die konden dan de waarde hunner polissen terugkrijgen, en zij zouden daarmede met weinig of geen verlies in een andere maatschappij kunnen worden opgenomen.

Zoodoende ware men gewaarborgd zoo niet tegen elke even. tualiteit, dan toch hoogst waarschijnlijk tegen geduchte bankroeten en tegen zwendelarijen, zooals die nog to veel plaats hebben, ook in ons raderland.

En heeft men op het gebied van Levensverzekering nog weinig of geen last gehad van zulke schandalen, het is beter krachtige maatregelen bij tijds te nemen, dan ze te gaan bedenken als reeds geduchte slagen zijn gevallen.

Met zulke maatregelen zou misschien de winst van sommige maatsehappijen wat verminderen; maar bij solide maatschappijen zou dat zooveel niet verschillen; want hooge renten mogen toch niet gezocht worden, dat is in den regel reeds een begin van insoliditeit. 
En al gaf dat nu ook eenig versehil; men moet niet uit het oog verliezen, dat, waar men toezicht aanbeveelt, er alleen sprake kan zijn van het belang der polishouders. De aandeelhouders verkeeren in geen ander geval dan bij elke vennootsehap die zich een of andere financieele of industrieele onderneming ten doel stelt. Mochten dan door strenge maatregelen niet zulke verbazend groote nitdeelingen kunnen plaats hebben, het is te verwachten, dat die dan ook des te zekerder zouden zijn.

Dordrecht. Corneille L. Landré, Wiskundige der Maatsclsappij van Levensverzekering te Dordrecht. 